\title{
REGULATORY ADMINISTRATION AND ORGANIZATIONAL RIGIDITY
}

\author{
Kenneth J. MeIer, University of Oklahoma \\ and \\ John P. Plumlee, Southern Methodist University
}

$\mathrm{G}$ OVERNMENT regulation of the private sector has long been a source of considerable controversy in American politics. The problems of regulation have concerned not only businessmen, politicians, and consumers, but economists and political scientists as well. The growth of the consumer movement as a force in national politics has added a new impetus to demands that "something" be done about regulation. Deciding what to do about regulation is not easy, however, either in terms of the conceptual issues involved or in terms of prescriptions for change. Although economists have devoted considerable attention to analyzing regulation and suggesting reforms, George Stigler ${ }^{1}$ has noted that they are often willing to make policy recommendations without sufficient knowledge of the impact of such recommendations. Their guidance, therefore, has been far from infallible. Political scientists have not been as persistently attentive to the problems of regulation with the notable exceptions of Lowi, McConnell, and Edelman. ${ }^{2}$ These scholars focused on the major political problems associated with regulation. One of the more important of these political problems, according to McConnell, is the relationship between public and private power.

In the regulatory context the problem of private versus public power may be seen as one of designating the beneficiaries of regulation, that is, who is regulation intended to benefit, and who does it benefit? Are the powers of the state applied to benefit select groups (the regulated industries) by protecting them from the rigors of competition, or are such powers exercised to maintain conditions as similar as possible to those of the free market and thus (in the view of economists) benefit a larger public, specifically consumers? While the question of who actually benefits is not fully settled, ${ }^{3}$ the dominant perspective holds that regulation has been for the benefit of the regulated and not for the consuming public. Critics who perceive this as a distortion of public policy goals attribute this outcome to the domination of regulatory agencies by the regulated interests. In short, what McGraw calls the "capture" thesis of regulatory behavior grips the imagination of many who have analyzed regulatory activity..$^{5}$ In the "capture" thesis, regulatory agencies are perceived as systematically favoring the regulated industries and systematically ignoring a larger "public interest." Public agencies are seen as tools for the advancement of private groups. The "capture" thesis reached its most complete expression in Marver Bernstein's book Regulating Business by Independent Regulatory Com-

Note: An earlier version of this paper was presented at the 1976 annual meeting of the Midwest Political Science Association, April 29 - May 1, 1976, Pick Congress Hotel, Chicago, Illinois.

'George J. Stigler, The Citizen and the State: Essays on Regulation (Chicago: Chicago University Press, 1975).

2 Theodore J. Lowi, The End of Liberalism (New York: Norton, 1969); Grant McConnell, Private Power and American Democracy (New York: Knopf, 1966); Murray Edelman, The Symbolic Uses of Politics (Urbana: University of Illinois Press, 1964).

"See: Stigler, The Citizen and the State; and Richard E. Posner, "Theories of Economic Regulation," Bell Journal of Economics and Management Science, Autumn, 1974.

"Thomas K. McCraw, "Regulation in America: A Review Article," Business History Review 49 (Summer 1975), 159-83.

'See Louis Kohlmeier, The Regulators (New York: Harper and Row, 1969); Edward F Cox et al. "The Nader Report" on the Federal Trade Commission (New York: Grossman, 1969); and Robert Fellmeth. The Interstate Commerce Omission (New York: Grossman, 1970). 
mission. ${ }^{6}$ Since then the idea of regulatory agency capture has become conventional wisdom in political science, and has done so without any serious empirical examination. This paper hopes to remedy that omission. We demonstrate that Bernstein's theory with some additional arguments is empirically testable and then test the theory with a limited data set. We take this approach because we believe that such simplistic solutions to regulatory problems as abolishing regulatory agencies are neither feasible nor perhaps desirable. Regulatory agencies, in contrast to the assumptions made by most economists, were not established to allocate resources efficiently but were established to remedy other problems. ${ }^{7}$ If regulation entails some deleterious second-order consequences or is not effectively performing its assigned tasks, then the first step in reform is not the abolition of the regulatory agencies but an examination of the reasons for failure.

\section{The Life Cycle of Regulatory Agencies}

The most popular explanation of regulatory agency failure was first summarized and presented by Marver Bernstein. Bernstein contends that all independent regulatory agencies follow the same historical pattern. This pattern is metaphorically equivalent to a human life cycle with four phases: gestation, youth, maturity, and old age.

\section{Gestation}

The climate which leads to the creation of a regulatory agency is filled with strong political forces. Powerful groups press their demands for some corrective action to remedy a policy or market failure. Opposed to the public demands are a narrower group of interests whose behavior would be regulated. The struggle culminates in the passage of remedial legislation and the creation of a regulatory agency. $^{8}$

\section{Youth}

From the legislative battle the new regulatory agency rises confident of public support and eager to wage war on the problem. The agency pursues its goals forcefully, concerned more with the interests of those responsible for creating the agency than with the interests of the regulated. Downs ${ }^{9}$ contends such aggressive policymaking is characteristic of most new agencies. The personnel attracted to the agency likely include many who pressed for the creation of the agency and, therefore, are Downsian zealots. Since new agencies have greater potential for growth and greater possibilities for aggrandizing personal power, agency employment will include younger, more ambitious, and possibly better trained personnel.

During the agency's youth changes occur in the environment of the agency that will eventually curtail its activism. Public support for the agency falters because the public has a short attention span and is diverted to other issues, because the public believes regulation automatically follows legislation, and because the public feels the battle is over. Actual regulation, unlike the fight to create an agency, is difficult to keep in the public eye. Establishing freight rates for cotton between Sioux City and Birmingham is not a salient issue to most people. With

\footnotetext{
${ }^{6}$ Marver H. Bernstein, Regulating Business by Independent Commission (Princeton: Princeton University Press, 1955).

"Paul Sabatier, "Social Movements and Regulatory Agencies," Policy Sciences 6 (1976), 30142 argues that many regulatory agencies were created to equalize group inputs, to maximize industry service, or to establish fair rates rather than to efficiently allocate resources.

"The reasons for creating a regulatory agency are important; they are political reasons concerned with market system failures or public policy failures. Rarely is the demand for a regulatory agency presented as an efficient allocation of scarce resources although the opposition to the agency may take this form.

${ }^{9}$ Anthony Downs, Inside Bureaucracy (Boston: Little, Brown, 1967).
} 
the decline in diffuse support come changes in specific support for the agency. Congressional interest in the agency drops, and the President loses interest because the agency is "independent" of his control. Since this decline in specific and diffuse support is not matched by a decline in specific opposition by the regulated interests, the environment creates pressures counter to vigorous regulation.

\section{Maturity}

The environmental change that occurs in the agency's youth leads to Bernstein's third stage in the life cycle, maturity. The agency must try to survive in a hostile environment where Congress, the President, and the public do not care and the organized interests (e.g., the regulated) would like to eliminate the agency. As Long $^{10}$ eloquently argues, the organization must seek new sources of support to maintain its power base and insure its survival. The most obvious source of such support is the regulated industry since the agency's actions are of low salience to almost everyone else. The agency and the interest gradually arrive at a mutually compatible agreement whereby the agency lessens its regulatory vigor and protects the industry from competition while the industry supports the agency in its political struggles for resources with the other political branches of government.

The maturity stage - what is normally defined as regulatory failure - is characterized by the following:

(a) Technical specialists (lawyers, economists, substantive specialists) come to dominate the agency. Each group is able to veto or at least stifle the other's policy proposals creating a dependence on precedent.

(b) The agency falls further and further behind in its workload as the result of the reliance on precedent and judicialized procedures. Backlogs tend to drive out policy planning. The agency looks backwards at what has been done rather than forward at what needs to be done.

(c) Congress and the President are indifferent to the agency workload problems; in fact, the presence of backlogs and the perceived interrelationship with the regulated influence the Congress and the President to deny to the agency the resources it needs to operate. The result is reduced appropriations and a cycle of buclgetary decline.

(d) The above factors increase the agency's identification with the interests of the regulated, often creating interdependence to the degree that the agency will recruit its personnel from the regulated industry. The industry also becomes a more frequent place for old regulators to retire. ${ }^{11}$

The result of all these factors is what can be termed organizational rigidity. The agency through its interrelationships with the industry, its judicialized procedures, its professional squabbles, and its resource decline will be unable or unwilling to respond to new pressures from the environment. The agency will continue past policies which may or may not benefit the regulated despite the need for innovative policy making. Rigidity occurs at the result of the mutual capture of agency and interest which results from changes in the political environment of the agency.

\section{Old Age}

The situation in old age for a regulatory agency is simply more of maturity only worse. The agency's personnel age and become even less aggressive, the relationships solidify, and the industry and the agency attempt to create an environment in which both can live though not necessarily prosper.

\footnotetext{
${ }^{10}$ Norton Long, The Polity (Chicago: Rand McNally, 1962).

${ }^{11}$ See Roger G. Noll, Reforming Regulation: An Evaluation of The Ash Council Proposals (Washington, D.C.: Brookings, 1971).
} 


\section{The Theory: Some Comments}

Bernstein's theory of regulatory agency decay is intuitively attractive and at least superficially appears to fit with political reality. Huntington' $\mathrm{s}^{12}$ analysis of the Interstate Commerce Commission revealed the initial aggressiveness and the eventual decline of the IGC. The Nader ${ }^{13}$ studies of the regulatory agencies never tire of establishing strong ties between the regulator and the regulated. The newer regulatory agencies such as the Environmental Protection Agency indeed appear more vigorous than older ones such as the Federal Communications Commission.

Despite its appeal the theory has several limitations. First, Bernstein applies the theory only to independent regulatory commissions. If environmental change leads to rigidity, the environmental demands on Departmental regulatory commissions (Food and Drug Administration, Occupational Safety and Health Administration, Packers and Stockyards Administration, etc.) will create similar pressures to reach an accommodation with the regulated industry. Simply because an agency resides within a department does not mean it is immune to the pressures of its environment. ${ }^{14}$ Second, Bernstein has not specified any time span for the decay of regulatory agencies. Without some indication as to the length of the life cycle, the theory will be difficult to falsify if youth is prolonged or shortened. Third, Bernstein notes that the aging process occurs at varying rates in different agencies. If this is true, using the theory of Downs and others, we would postulate that the rate of aging is related to several environmental variables such as political support, interest group strength, and complexity of the policy area. Examining these relationships is important because they may inform us as to how the process can be delayed if it cannot be prevented. Fourth, some agencies according to Sabatier were meant to be captured. Agencies such as the Federal Communications Commission, the Atomic Energy Commission and the Civil Aeronautics Board were established at the request of the regulated interest to protect them from the uncertainties of the environment. The life cycle theory may be inappropriate for agencies designed to protect rather than regulate. Fifth, if the aging cycle occurs at varying rates and is the result of environmental pressures, is it not possible to revitalize an agency by manipulating its environment? If the environmental constraints are identified, the options for remedial policy-making are extended far beyond the simple abolish or leave things as they are options that are presented. Since some agencies (e.g., the current FTC) show signs of revitalization, the life cycle argument is too pessimistic and does not fully deal with regulatory agency change. Sixth, the theory portrays agencies as passive actors at the whim of the environment. Rourke, however, has demonstrated that agencies not only respond to environmental demands but often shape the environment's demands on the agency. If this is true, creative agency leadership provides possibilities for preventing decay by creating an environment more amenable to vigorous regulation.

\section{A Model of Agency Degay}

From the theory of Bernstein supplemented by the insights of Downs, Rourke, Long, and others we can extract the important variables in the "life cycle" of regulatory agencies and construct a model. The first variable in the model is the age of the agency. Age within the bounds of this theory is chronological age rather than

\footnotetext{
${ }^{13}$ Samuel P. Huntington, "The Marasmus of the ICC," Yale Law Journal 61 (April 1952): 467-509.

${ }^{13}$ See Cox, "The Nader Report"; Fellmeth. The Interstate Commerce Omission; Mark J. Green, The Monopoly Makers (New York: Grossman. 1973); James S. Turner. The Chemical Feast (New York: Grossman. 1970).

"Francis Rourke, Bureaucracy, Politics, and Public Policy (Boston: Little, Brown, 1976): Downs, Inside Bureaucracy.
} 
a more complex multidimensional concept such as maturity.$^{15}$ The second variable is the quality of specific political support for the agency in terms of other political elites and the balance between general and regulated interests. The third variable is the relationship of the agency to the regulated industry which may vary from one extreme of capture to the other extreme of total independence. The fourth and final variable is the degree of rigidity - the ability of the agency to respond to demands placed on it by the environment.

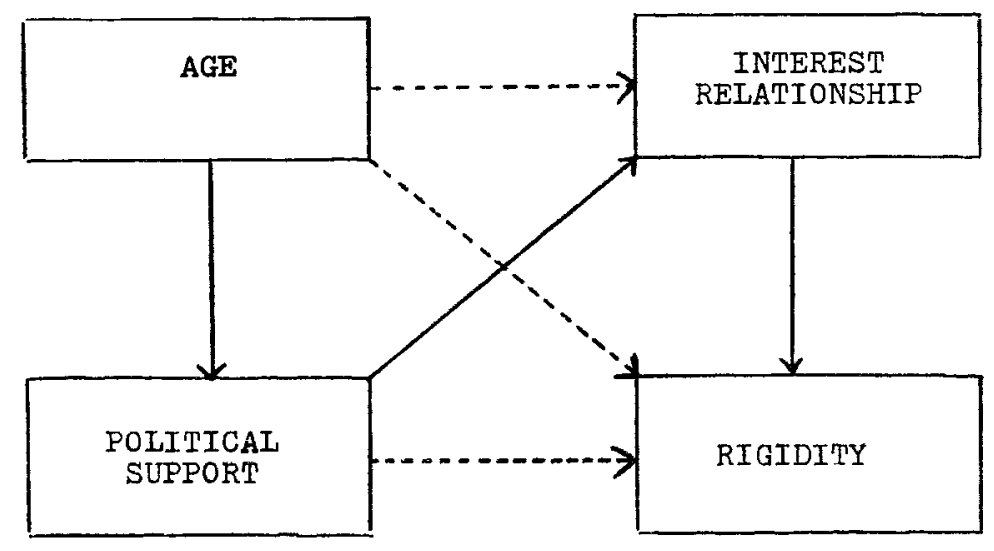

Figure 1. The Agency "Rigitity Cyale" Modex

With some limiting assumptions the four variables can be combined as a model as shown in Figure 1.16 Age is the key variable; it affects the degree of political support and through political support has an impact on interest relationships and through both variables an impact on rigidity. Age, in theory, has only an indirect impact on rigidity and interest relationships. Political support affects the agency's interest relationships and through interest relationships the rigidity of the agency. The relationships of the agency to the regulated directly impact on the rigidity of the agency. The reader should be aware that several other relationships that the theory does not specifically note (denoted with dotted lines) are possible.

From the model presented and the more detailed theory of regulatory agency decay six general hypotheses are suggested:

$\mathrm{H}_{1}$ : The greater the age of the regulatory agency, the greater the rigidity of the agency.

$\mathrm{H}_{2}$ : The greater the age of the regulatory agency, the more likely it is to be "captured" by the regulated interest.

$\mathrm{H}_{3}$ : The greater the age of the agency, the lower the diffuse support for the agency.

$H_{1}$ : The smaller the political support for the agency, the greater the probability of clientele capture.

$\mathrm{H}_{5}$ : The smaller the agency's political support, the greater the probability of rigidity.

$H_{i j}$ : The stronger the interdependent relationship between the regulated and the regulator, the more rigid the agency is.

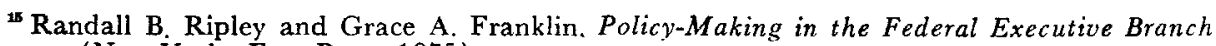
(New York: Free Press, 1975).

${ }^{16}$ Specifically the model assumes a linear recursive model. The aging process is, therefore, irreversible within the assumptions of this model. 


\section{Some Measures of the Variables}

Of all the variables used in this study, the easiest to measure and the least complicated is the age of the agency. Age is measured as the chronological age of the agency. Although this is contrary to Ripley and Franklin's finding that agency maturity is a multidimensional concept, the single operationalization is congruent with Bernstein's theory. ${ }^{17}$

Political support is a combination of three factors: congressional support, presidential support, and public support. Congressional support, ideally, could be measured in two ways - first, in terms of statements by individual members of Congress concerning the agencies or their activities, or, second, in terms of the behavior of Congress as a unit - allowing agency expenditure growth, decreased limitation on personnel, and granting a large portion of the resources requested. Our research will concentrate on the behavior of Congress overall rather than on the opinions of individual members of Congress. Three indicators of congressional support will be used, the budget growth rate allowed by Congress, the personnel growth rate allowed by Congress, and the appropriations success rate. ${ }^{18}$

Presidential support can be measured by the growth rate of the executive budget for each agency and by the quality of presidential appointments. Presidential statements concerning regulation could also be used although we do not do this for the same reason that we do not analyze the statements of members of Congress. This reason is the dominant mythos surrounding the American view of regulation, that is, that regulation is "bad." It is easy to criticize regulation and is probably good politics to do so. Clearly, if there were a direct correlation between what has been said about the need for reforming regulation and what has actually been done about reforming it, all of the problems of regulation would probably have been solved long ago. We exempt statements, therefore, from this analysis and concentrate instead on what is actually done by Congress and the President. This analysis will use only the growth rate of the President's budget as an indicator of presidential support. ${ }^{19}$

Interest relationships (captivity) encompass the relationships between the regulators and the regulated. Personnel processes provide two traditional indicators of this variable - where entering personnel are recruited from (industry or other) and where the personnel retire. The relationship with the interests regulated can also be measured by a content analysis of group testimony before Congress. Although such testimony is spotty for the older agencies in their initial years, it does provide a rough indicator of group support. ${ }^{20}$ In addition, the use of consent decrees rather than court cases indicates that the agency and the industry are beginning to accommodate each other. A content analysis of agency decisions, an onerous and tedious task, could show the change in relationships over time. Al-

${ }^{17}$ The use of chronological age does not eliminate all the difficulties with the concept. The decision as to when the agency was founded is not as simple as it seems. Many regulatory agencies such as the FCC and the FAA had predecessor agencies and staffed themselves from these predecessor agencies. We used the date the agency was created, not the date of the predecessor agency. For the opposite view see Herbert Kaufman. Are Gozernment Organizations Immortal? (Washington, D.C.: Brookings, 1976).

${ }^{18}$ The budget and personnel growth rates are calculated by dividing one fiscal year's allotment by the previous fiscal year's, subtracting one and converting to a percent gain or loss. The success rate is the percentage of the agency's budget request that is granted by Congress. All figures are from the Budget of the United States Government for the appropriate fiscal years.

10 The interest support measure was constructed from a content analysis of group testimony on the agency's budget. Variables included direction (positive or negative) and specificity (entire agency or program only). Coding details are available on request.

${ }^{20}$ We have not included an indicator of general public support because diffuse public support would be difficult if not impossible to measure since specific regulatory agencies are of low salience to the average person. We do not know of any regulatory agency with a reserve of diffuse public support. 
though these later behavioral variables are often useful in single agency case studies, the behaviors are rarely comparable across agencies. We must limit our indicators, therefore, to the personnel process and to testimony.

Several objective and partially reliable indicators of rigidity are also available. Bernstein's theory suggests that rigidity is reflected in increased backlogs, decline in efficiency, drop off in expertise, and increased dominance by lawyers. Downs adds the age of the administrators and increased turnover as manifestations of rigidity.

The indicators for support, interest relationships, and rigidity have one major advantage and one major disadvantage. The advantage is that all are available from accessible sources to researchers willing to expend the effort. The disadvantage is each indicator is a long way from a valid indicator of the variable in question. For this reason any definitive attempt to assess the agency decay thesis will need to use a multiple indicators approach. In addition to the indicator problems, the type of analysis necessary to fully answer the questions raised must be longitudinal (a few agencies over a long period of time) rather than cross sectional (many agencies at the same time). Since Bernstein feels agencies age at different rates, cross sectional analysis cannot provide a fully adequate test of the theory because agency trends will be affected by different rates of aging. The theory cannot be rejected if an older agency is less rigid than a younger agency.

In an attempt to evaluate portions of this theory, we gathered data on eight regulatory agencies - the Federal Communications Commission (FCC), The Civil Aeronautics Board (CAB), the Federal Trade Commission (FTG), the National Labor Relations Board (NLRB), the Federal Aviation Administration (FAA), the National Transportation Safety Board (NTSB), the Occupational Safety and Health Administration (OSHA), and the Packers and Stockyard Administration (PSA). The data gathered over the entire life span of the agency were taken from federal budgets, the Government Organization Manual, Agency Annual Reports, and standard biographical sources.

\section{Testing the Theory}

This section will attempt several tests of the theory. Since the tests are done with only a few indicators and a few agencies the results must be interpreted as speculative rather than definitive. Our purpose is to examine the merits of the theory within the limits of the present data sources. This procedure should permit us to examine the utility of Bernstein's theory as a description of reality.

\section{Age and Political Support}

If the theory of regulatory decay holds, hypothesis 3 predicts that age and political support are inversely related. This implies that congressional and presidential support for an agency will be strongest in the agency's youth; in later years the agency will have difficulty maintaining its budget base. Table 1 shows the congressional appropriations growth rate for the eight regulatory agencies. ${ }^{21} \mathrm{Al}-$ though the correlations between agency age and its growth rate in Table 14 are all negative, an examination of the data in Table 1 reveals Downs and Bernstein are only partially correct. In the initial years of the agency, the agency grows rapidly, exceeding the growth rate of the entire federal budget. After four to eight years of growth, some decline and reversal sets in. After the initial decline the agency experiences a great deal of fluctuation rather than continued decline in appropria-

\footnotetext{
2n Table 1 as well as Tables 2 through 13 present the data as four-year averages. The single year figures are not reported because the data are too numerous to identify trends clearly and because single years are often subject to random fluctuations. The correlations reported in Table 14, however, use the year by year figures so that sufficient data points would be available for analysis. Neither procedure affects the conclusions drawn.
} 
tions as the theory predicts. Table 2 (The Personnel Growth Rate) and Table 3 (The Presidential Growth Rate) plus the respective correlations in Table 14 show a similar pattern.

TAble 1. Growth Rate in Agency Appropriations Permitted by Congress

\begin{tabular}{|c|c|c|c|c|c|c|c|c|}
\hline \multirow[b]{2}{*}{ Year } & \multicolumn{8}{|c|}{ Agenci } \\
\hline & $\overline{F C C}$ & $F T C$ & $N L R B$ & $F A A$ & $C A B$ & $\overline{P S A}$ & $N T S B$ & $\widehat{O S H A}$ \\
\hline $1973-75$ & 17.4 & 18.4 & 10.0 & 6.6 & 6.3 & 7.8 & 13.0 & 41.4 \\
\hline 1969-72 & 12.7 & 13.8 & 10.7 & 10.0 & 6.1 & 9.4 & 15.1 & \\
\hline 1965-68 & 4.5 & 6.0 & 9.3 & 3.2 & -7.7 & & & \\
\hline 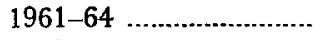 & 7.2 & 15.3 & 9.4 & 8.8 & 9.0 & & & \\
\hline $1957-60$ & 14.0 & 10.5 & 15.5 & 34.4 & 12.0 & & & \\
\hline $1953-56$ & 2.8 & 1.6 & .6 & & -5.3 & & & \\
\hline $1949-52$ & 1.5 & 5.7 & 14.1 & & 6.5 & & & \\
\hline 1945-48 & 2.7 & 12.0 & 15.8 & & 26.2 & & & \\
\hline $1941-44$ & 49.3 & -3.9 & 1.2 & & 4.2 & & & \\
\hline $1937-40$ & -3.9 & 8.6 & 101.0 & & & & & \\
\hline 1933-36 & 72.2 & 3.3 & & & & & & \\
\hline 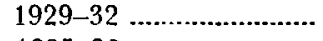 & & 14.7 & & & & & & \\
\hline $1925-28$ & & -1.4 & & & & & & \\
\hline 1921-24 ................................. & & -8.3 & & & & & & \\
\hline $1917-20$ & & 52.3 & & & & & & \\
\hline $1913-16$ & & 134.2 & & & & & & \\
\hline
\end{tabular}

Table 2. Growth Rate in Agengy Personnel Permitted by Congress

\begin{tabular}{|c|c|c|c|c|c|c|c|c|c|}
\hline \multirow{2}{*}{\multicolumn{2}{|c|}{ Year }} & \multicolumn{8}{|c|}{ AGENGY } \\
\hline & & $\overline{F C C}$ & $F T C$ & $N L R B$ & $F A A$ & $C \widehat{A B}$ & $P S A$ & NTSB & OSHA \\
\hline $1973-75$ & . & 6.1 & 4.6 & 4.0 & 2.3 & .8 & .9 & 1.4 & 8.8 \\
\hline $1969-72$ & . & 1.1 & 2.9 & -1.0 & 4.5 & 1.2 & 1.8 & 2.8 & \\
\hline $1965-68$ & ......................... & 1.3 & 1.4 & 4.1 & 0.0 & -5.9 & & & \\
\hline $1961-64$ & . & 1.8 & 12.3 & 3.9 & 5.6 & 4.0 & & & \\
\hline $1957-60$ & .......................... & 6.2 & 4.5 & 10.7 & 23.6 & 5.3 & & & \\
\hline $1953-56$ & 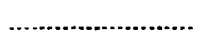 & -2.1 & -4.2 & -3.6 & & .2 & & & \\
\hline $1949-52$ & 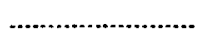 & -2.6 & 4.9 & -4.4 & & -.5 & & & \\
\hline $1945-48$ & 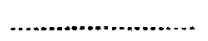 & -8.6 & 12.6 & 27.4 & & 19.9 & & & \\
\hline $1941-44$ & ........................... & 45.0 & -9.1 & -4.3 & & 2.6 & & & \\
\hline $1937-40$ & 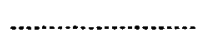 & -4.1 & 5.4 & 61.6 & & & & & \\
\hline $1933-36$ & . & 32.8 & 10.8 & & & & & & \\
\hline $1929-32$ & .............................. & & 8.5 & & & & & & \\
\hline $1925-28$ & ................................ & & .1 & & & & & & \\
\hline $1921-24$ & - & & -7.5 & & & & & & \\
\hline $1917-20$ & 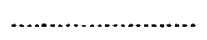 & & 43.1 & & & & & & \\
\hline $1913-16$ & . & & 56.6 & & & & & & \\
\hline
\end{tabular}

Before evaluating hypothesis 3 , two additional facts should be noted. First, the reason why these agencies grow rapidly initially is that growth is easier to achieve when the previous year's budget is small. Any growth is a large percentage of the base when the base is small. This pattern should appear in not only regulatory agencies but all agencies of the federal government. Second, the pattern, despite using four-year intervals, fluctuates greatly. Some agencies fifty years old and more are able to achieve annual budget growth rates of nearly 20 percent. Presidential and congressional support does not disappear with age; it often grows. This conclusion is supported by the correlations between age and the various growth rates for each agency (see Table 14). The newer agencies, reflecting the initial down- 
turn, have the highest negative correlations. In the older agencies age is slightly correlated in the predicted direction as a residual result of the first few years. When these early years are deleted from the analysis, the relationship between age and budget growth disappears.

Table 4 shows the budget success rate (percent of requested appropriations that were granted) for the eight agencies. Since, as Fenno noted, success and growth are independent, we are not surprised that no pattern appears. The success rate of the NLRB and the FCC are the only ones (see Table 14) that show negative correlations with age; in both agencies the relationship is unduly influenced by large initial success rates. The other five agencies show positive correlations between success in budgeting and age, contrary to the theory's prediction. ${ }^{22}$

TAble 3. Growth Rate in Agency Appropriations Permited by President

\begin{tabular}{|c|c|c|c|c|c|c|c|c|}
\hline \multirow[b]{2}{*}{ Year } & \multicolumn{8}{|c|}{ AGENGY } \\
\hline & $\overline{F C C}$ & $F T C$ & NLRB & $F A A$ & $C A B$ & $\overline{P S A}$ & $N T S B$ & $\widehat{O S H A}$ \\
\hline $1973-75$ & 4.7 & 8.0 & 7.6 & -14.3 & -3.7 & 2.7 & 5.1 & 13.6 \\
\hline $1969-72$ & 10.6 & 7.1 & 4.1 & .1 & -11.5 & 8.2 & 13.1 & 34.5 \\
\hline 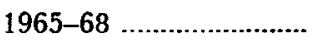 & 3.1 & 5.7 & 7.8 & .4 & -3.0 & & & \\
\hline $1961-64 \ldots \ldots \ldots \ldots$ & 5.9 & 12.7 & 8.0 & 9.6 & 4.4 & & & \\
\hline $1957-60 \ldots \ldots \ldots \ldots \ldots$ & 8.2 & 8.8 & 8.9 & 35.3 & 4.1 & & & \\
\hline $1953-56$ & 9.6 & 8.5 & 2.7 & & 18.4 & & & \\
\hline $1949-52 \ldots \ldots \ldots \ldots$ & 1.1 & 12.4 & 16.4 & & 12.3 & & & \\
\hline $1945-48 \ldots \ldots \ldots \ldots \ldots$ & 7.4 & 18.5 & 50.7 & & 22.5 & & & \\
\hline 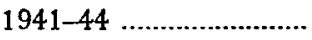 & 6.8 & -1.1 & 5.1 & & 9.6 & & & \\
\hline $1937-40$ & -9.5 & 5.1 & 38.8 & & & & & \\
\hline $1933-36$ & & -13.4 & & & & & & \\
\hline 1929-32 ....................... & & 5.5 & & & & & & \\
\hline 1925-28 & & -3.6 & & & & & & \\
\hline $1921-24 \ldots \ldots \ldots \ldots$ & & 4.4 & & & & & & \\
\hline $1917-20 \ldots \ldots \ldots \ldots \ldots \ldots \ldots$ & & $*$ & & & & & & \\
\hline $1913-16$ & & * & & & & & & \\
\hline
\end{tabular}

* Data not available.

The first four tables do not lend a great deal of support to Bernstein's thesis. Although growth rates are initially high and do decline, this is a normal pattern that results when an agency is built out of nothing. Bernstein incorrectly generalized from the initial years of the agency and did not notice that regulatory agencies often experience rapid periods of growth throughout their lives. Additional environmental influences (e.g., the party controlling the White House and the Congress, the existence of war, etc.) as they appear may be better explanatory variables than just agency age.

\section{Age and the Interest Relationship}

Hypothesis 2 predicts that a regulatory agency as it ages develops a more positive relationship with the regulated industry. This hypothesis implies that older agencies will recruit their personnel more from the regulated industry, will have more of their personnel retire to the regulated, and the regulated's expressed support for the agency will increase as the agency moves into the industry's orbit.

First, Table 5 reveals that recruiting agency personnel from the industry at elite levels is a phenomenon that varies widely across agencies and across time within agencies. Clearly Table 5 does not reveal regulatory agencies increasingly rely

22 It appears to the authors that success rates have improved generally in recent years. If this is true it reverses a long standing role of Congress in cutting presidential requests. A replication of Richard Fenno, The Power of the Purse (Boston: Little, Brown, 1962) is in order to see if congressional behavior has changed. 
on the regulated for their personnel. In fact, the NLRB, the FAA, and the CAB relied heavily on the regulated industry in their formative years. As these agencies aged, they recruited more from the industry although they never relied exclusively on the industry for most of their higher personnel. As the agencies aged further, recruitment from the industry leveled off and actually declined. Table 5 shows recruitment from the regulated industry is less frequent now than it was in the past. Table 14 shows the wide range in the relationships between industry recruiting and age; negative relationships were found for the NLRB, the FAA, and the CAB. The positive relationships for the $F C C$ and the $F T C$ reflect the initial increase in recruiting from the regulated but not the later decline. This test of Bernstein's hypothesis finds the theory lacking.

Table 4: Percent of Appropriation Requested of Congress that is Regeived

\begin{tabular}{|c|c|c|c|c|c|c|c|c|c|}
\hline \multirow{2}{*}{\multicolumn{2}{|c|}{ Year }} & \multicolumn{8}{|c|}{ AGengy } \\
\hline & & $F C C$ & $F T C$ & $N L R B$ & FAA & $C A B$ & PSA & $N T S B$ & $\overline{O S H A}$ \\
\hline $1973-75$ & . & 110.8 & 108.4 & 102.9 & 123.5 & 112.5 & 105.1 & 106.1 & 105.2 \\
\hline $1969-72$ & 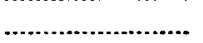 & 101.9 & 106.1 & 105.6 & 116.2 & 121.9 & 100.1 & 101.8 & \\
\hline $1965-68$ & . & 101.4 & 100.3 & 100.4 & 101.1 & 95.0 & & & \\
\hline $1961-64$ & 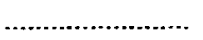 & 101.8 & 102.3 & 102.2 & 97.5 & 103.8 & & & \\
\hline $1957-60$ & ............................. & 105.5 & 102.1 & 106.6 & 101.9 & 108.2 & & & \\
\hline $1953-56$ & . & 94.6 & 94.6 & 98.5 & & 77.0 & & & \\
\hline $1949-52$ & ............................... & 100.0 & 99.0 & 97.9 & & 94.4 & & & \\
\hline $1945-48$ & .......................... & 89.5 & 95.0 & 85.2 & & 100.6 & & & \\
\hline $1941-44$ & ......................... & 139.6 & 97.2 & 96.5 & & 100.3 & & & \\
\hline $1937-40$ & 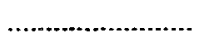 & 108.3 & 103.8 & 162.6 & & & & & \\
\hline $1933-36$ & . & 130.8 & 118.3 & & & & & & \\
\hline $1929-32$ & ............................... & & 108.6 & & & & & & \\
\hline $1925-28$ & 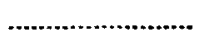 & & 100.9 & & & & & & \\
\hline $1921-24$ & 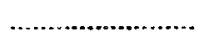 & & 88.6 & & & & & & \\
\hline $1917-20$ & 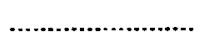 & & 84.8 & & & & & & \\
\hline $1913-16$ & ............................. & & 68.6 & & & & & & \\
\hline
\end{tabular}

TAble 5. Percent of Agency Elites Regruited from the Regulated Interest

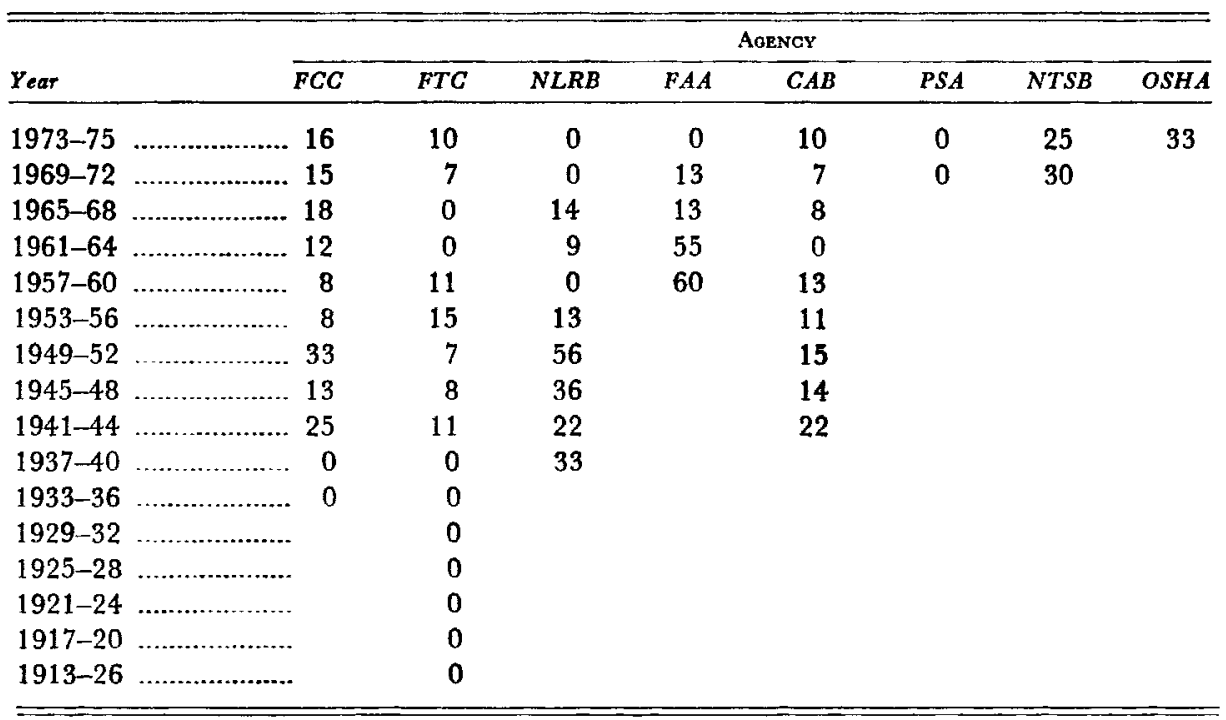


Second, members retiring to work in the regulated industry ${ }^{23}$ is hardly universal, but occurs with sufficient frequency to cause concern. According to a 1959 congressional hearing on regulation, an average of 3.3 percent of retirees go to work for the regulated industry. ${ }^{24}$ Table 6 shows elite retirement to the regulated is not only infrequent but has decreased in recent years. Table 14 shows a negative correlation (at times strongly negative) between age and industry retirement for four of the agencies and no relationship for the FCG. Bernstein's hypothesis of an increasing trend is not found in the data.

TABle 6. Pergentage of Agengy Elites Who Retire to the Regulated Industry

\begin{tabular}{|c|c|c|c|c|c|c|c|c|}
\hline \multirow[b]{2}{*}{ Year } & & \multicolumn{7}{|c|}{ AGengy } \\
\hline & $\overline{F C C}$ & $F T \bar{C}$ & $N L R B$ & $F A A$ & $C A B$ & $P S A$ & $\overline{N T S B}$ & $\overline{O S H A}$ \\
\hline $1973-75$ & . & 0 & 0 & 14 & 0 & 0 & 0 & 0 \\
\hline $1969-72$ & 5 & 0 & 0 & 13 & 7 & 0 & 0 & \\
\hline $1965-68$ & $\ldots$ & 0 & 0 & 13 & 8 & & & \\
\hline $1961-64$ & 15 & 8 & 0 & 33 & 9 & & & \\
\hline $1957-60$ & ..................... 8 & 6 & 10 & 60 & 6 & & & \\
\hline $1953-56$ & 13 & 0 & 13 & & 11 & & & \\
\hline 1949-52 & 13 & 0 & 33 & & 23 & & & \\
\hline $1945-48$ & 10 & 0 & 22 & & 14 & & & \\
\hline $1941-44$ & 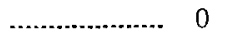 & 0 & 11 & & 11 & & & \\
\hline $1937-40$ & 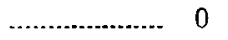 & 0 & 11 & & & & & \\
\hline $1933-36$ & 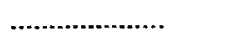 & 0 & & & & & & \\
\hline 1929-32 & ...................... & 0 & & & & & & \\
\hline $1925-28$ & - & 11 & & & & & & \\
\hline $1921-24$ & ...................... & 0 & & & & & & \\
\hline $1917-20$ & 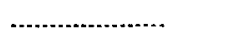 & 0 & & & & & & \\
\hline $1913-16$ & ............................. & 0 & & & & & & \\
\hline
\end{tabular}

TABLE 7. The Direction of Interest Group Support for the Agengy

\begin{tabular}{|c|c|c|c|c|c|c|c|c|c|}
\hline \multirow{2}{*}{\multicolumn{2}{|c|}{ Year }} & \multicolumn{8}{|c|}{ AGENGY } \\
\hline & & $\overparen{F C C}$ & $F T C$ & NLRB & $F A \bar{A}$ & $C A B$ & $P S A$ & NTSB & $O S H A$ \\
\hline $1973-75$ & .......................... & 0 & 0 & 0 & + & 0 & - & 0 & + \\
\hline $1969-72$ & .................... & 0 & - & 0 & - & 0 & + & 0 & \\
\hline $1965-68$ & ............................... & 0 & 0 & + & - & + & & & \\
\hline $1961-64$ & ................................ & + & - & 0 & 0 & + & & . & \\
\hline $1957-60$ & ............................... & + & - & - & + & + & & & \\
\hline $1953-56$ & ............................ & 0 & 0 & 0 & & 0 & & & \\
\hline $1949-52$ & .......................... & 0 & + & 0 & & - & & & \\
\hline $1945-48$ & 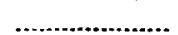 & 0 & 0 & - & & 0 & & & \\
\hline $1941-44$ & 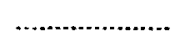 & 0 & + & - & & & & & \\
\hline $1937-40$ & ..................... & & - & & & $\therefore$ & & & \\
\hline $1933-36$ & . & & - & & & & & & \\
\hline $1929-32$ & ..................... & & 0 & & & & & & \\
\hline $1925-28$ & .......................... & & 0 & & & & & & \\
\hline $1921-24$ & 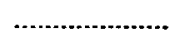 & & $*$ & & & & & & \\
\hline $1917-20$ & ………… & & * & & & & & & \\
\hline $1913-16$ & 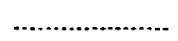 & & * & & & & & & \\
\hline
\end{tabular}

* Data not available.

${ }^{23}$ The "regulated industry" is not an unambiguous term. Some cases are clear-cut such as when a $\mathrm{CAB}$ employee goes to work for an airline. Other cases are not so clear. Many retire to private law practice or consulting which serve primarily the regulated industry. For the agency elites, we defined the term conservatively and did not include private law practice or consulting where the business was not unambiguously one which served the regulated.

${ }^{24}$ United States Congress, House Committee on Interstate and Foreign Commerce, Special Subcommittee on Legislative Oversight, Independent Regulatory Commissions (Washington, D.C.: U.S. Government Printing Office, 1960). 
Third, Table 7 (Industry Expressions of Support) adds little to confirming the theory of regulatory agency decay. Table 14 shows support does grow with age but that the correlations are very small. The positive correlations are more a function of the increased tendency to testify before Congress rather than increased support for the agency. Compared to other agencies, the expressed support for regulatory agencies is very small exceeding that only of the Treasury Department and other non-clientele agencies.

The findings concerning agency age and the interest relationship are clear. None of the data unambiguously support the contention that regulators and the industry form a more symbiotic relationship as time passes. In most cases the data directly refute the hypothesis. The findings must be qualified since we have examined only personnel flows and public statements rather than agency behavior. Pending a more comprehensive analysis, hovever, we must conclude that the agency and the regulated do not become more interdependent over time. ${ }^{25}$

\section{Age and Rigidity}

Hypothesis 1 predicts that as a regulatory agency ages, its behavior will become more rigid. Since the agency personnel are expected to decline in quality with age, older regulatory agencies should have larger separation rates, less expertise, and older leadership. Rigidity also includes judicialization of procedures; age, therefore, should be positively correlated with the percentage of employees that are lawyers. Finally, age should be associated with increased backlogs and declines in agency efficiency.

The turnover of agency executive personnel for our eight agencies is independent of the age of the agency (Table 8 ). Table 14 reveals that the correlation between the two variables is nearly zero in five of the seven agencies and negative for another. Only OSHA fits the predicted pattern of increasing turnover. OSHA's pattern can be explained. Since OSHA is a relatively new agency that has become controversial, the normal low turnover for a new agency has escalated rapidly. With time OSHA will resemble the other regulatory agencies.

Table 8. Pergentage Turnover of Agency Elites

\begin{tabular}{|c|c|c|c|c|c|c|c|c|}
\hline \multirow[b]{2}{*}{ Year } & & \multicolumn{7}{|c|}{ Agengy } \\
\hline & $\overline{F C C}$ & $F T C$ & $\overline{N L R B}$ & $\overline{F A A}$ & $\overline{C A B}$ & $\overline{P S A}$ & $N T S B$ & $O S H A$ \\
\hline $1973-75$ & 34 & 43 & 25 & 35 & 42 & 0 & 5 & 75 \\
\hline $1969-72$ & 24 & 31 & 25 & 28 & 23 & 0 & 15 & \\
\hline $1965-68$ & 15 & 10 & 2 & 28 & 20 & & & \\
\hline $1961-64$ & 24 & 40 & 26 & 35 & 35 & & & \\
\hline $1957-60$ & $\ldots$ & 10 & 18 & 26 & 14 & & & \\
\hline $1953-56$ & 29 & 26 & 22 & & 30 & & & \\
\hline $1949-52$ & .................. 18 & 23 & 17 & & 21 & & & \\
\hline $1945-48$ & 40 & 31 & 31 & & 48 & & & \\
\hline $1941-44$ & ..................... 23 & 20 & 38 & & 27 & & & \\
\hline $1937-40$ & 20 & 7 & 27 & & & & & \\
\hline $1933-36$ & . & 26 & & & & & & \\
\hline 1929-32 & . & 4 & & & . & & & \\
\hline $1925-28$ & ....................... & 13 & & 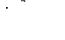 & & & & \\
\hline $1921-24$ & , n.................. & 14 & & & & & & \\
\hline $1917-20$ & . & 42 & & & & & & \\
\hline $1913-16$ & , & 0 & & & & & & \\
\hline
\end{tabular}

\footnotetext{
${ }^{25}$ This does not mean these agencies are not at times "captured" by the industry, only that capture is not positively related to the age of the agency. The charge of capture has been documented by others (see footnote 5 ), and this paper does not challenge those findings.
} 
Table 9. Percentage of Agency Elites with Prior Expertise at Time of Appointment

\begin{tabular}{|c|c|c|c|c|c|c|c|c|}
\hline \multirow[b]{2}{*}{ Year } & & \multicolumn{7}{|c|}{ AgENCY } \\
\hline & FCC & FTC & $N L R B$ & $F A A$ & $C A B$ & $\overline{P S A}$ & $N \overline{T S B}$ & $\overline{O S H A}$ \\
\hline $1973-75$ & $\ldots$ & 10 & 88 & 86 & 63 & 67 & 75 & 100 \\
\hline $1969-72$ & ...................... 45 & 31 & 73 & 88 & 71 & 67 & 80 & \\
\hline $1965-68$ & 62 & 64 & 71 & 100 & 58 & & & \\
\hline $1961-64$ & 74 & 58 & 73 & 89 & 73 & & & \\
\hline $1957-60$ & ............... 31 & 56 & 100 & 80 & 56 & & & \\
\hline $1953-56$ & 62 & 31 & 67 & & 61 & & & \\
\hline $1949-52$ & 63 & 43 & 78 & & 77 & & & \\
\hline $1945-48$ & 62 & 62 & 73 & & 57 & & & \\
\hline $1941-44$ & 50 & 44 & 56 & & 56 & & & \\
\hline $1937-40$ & 64 & 50 & 50 & & & & & \\
\hline $1933-36$ & 67 & 38 & & & & & & \\
\hline 1929-32 & 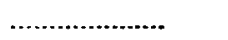 & 29 & & & & & & \\
\hline $1925-28$ & . & 44 & & & & & & \\
\hline $1921-24$ & .......................... & 43 & & & & & & \\
\hline $1917-20$ & 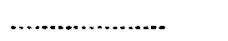 & 30 & & & & & & \\
\hline $1913-16$ & . & 20 & & & & & & \\
\hline
\end{tabular}

Table 9 presents the percentage of agency elites with prior expertise in regulation or the substantive area being regulated. The only thing that can be said for expertise is that it does not co-vary with the age of the agency. Expertise fluctuates moderately in some agencies and more so in others such as the FTC. In general these agencies reflect the high value placed on expertise with the more recently created agencies (PSA, NTSB, and OSHA) ranking very high from their inception. Although the correlations within agencies (Table 14) show four of the five relationships are positive (a rejection of Bernstein), most relationships are too small for certainty.

Table 10 presents the average age of the agency elites over time. The most notable fact is that the age of agency executives varies little. Table 14, however, shows that as agencies age, the average age of their executives increases. Although an upper limit to executive ages must dampen this trend eventually, the prediction of a positive relationship appears to hold.

TABLE 10. Average Age of Agency Elites

\begin{tabular}{|c|c|c|c|c|c|c|c|c|}
\hline \multirow[b]{2}{*}{ Year } & & \multicolumn{7}{|c|}{ Agency } \\
\hline & $\overline{F C C}$ & FTC & $N L R B$ & $\overline{F A A}$ & $C A B$ & $\overline{P S A}$ & $N T S B$ & $O S H A$ \\
\hline $1973-75$ & 60 & 54 & 49 & 56 & 57 & 57 & 54 & 43 \\
\hline $1969-72$ & ............... 52 & 54 & 56 & 54 & 57 & 57 & 53 & \\
\hline $1965-68$ & 54 & 54 & 57 & 55 & 57 & & & \\
\hline $1961-64$ & $\ldots 2$ & 54 & 56 & 48 & 53 & & & \\
\hline $1957-60$ & ..................... 51 & 53 & 53 & 46 & 50 & & & \\
\hline $1953-56$ & 52 & 54 & 51 & & 53 & & & \\
\hline 1949-52 & 50 & 55 & 51 & & 48 & & & \\
\hline $1945-48$ & .................. 48 & 59 & 53 & & 47 & & & \\
\hline $1941-44$ & .................. 49 & 61 & 48 & & 45 & & & \\
\hline $1937-40$ & ............... 48 & 60 & 46 & & $\cdot$ & & & \\
\hline $1933-36$ & .......... 56 & 53 & & & & & & \\
\hline $1929-32$ & ......................... & 59 & & & & & & \\
\hline 1925-28 & ........................ & 57 & & & & & & \\
\hline $1921-24$ & ..................... & 54 & & & & & & \\
\hline $1917-20$ & - & 50 & & & & & & \\
\hline $1913-16$ & . & 48 & & & & & & \\
\hline
\end{tabular}


Our theory predicts that as agencies age, their procedures will become more judicialized resulting in increased backlogs and a decline in efficiency. The next three tables examine these predictions. The relationship between legal training of agency elites and the age of the agency forms a consistent pattern. Although some fluctuation exists, regulatory agencies appear to include more lawyers as they age (Table 11). Table 14 reveals that this relationship holds for all agencies except the NTSB. Despite the one exception the data indicate that as regulatory agencies age, lawyers are more likely to be in positions of authority.

Table 11. Percentage of Agengy Elites with Legal Training

\begin{tabular}{|c|c|c|c|c|c|c|c|c|}
\hline \multirow[b]{2}{*}{ Year } & & \multicolumn{7}{|c|}{ AgENCY } \\
\hline & $\overline{F C C}$ & $F T C$ & $\overline{N L R B}$ & $\overline{F A A}$ & $C A B$ & $\overline{P S A}$ & $\overline{N T S B}$ & $\overline{O S H A}$ \\
\hline $1973-75$ & ............... 58 & 100 & 100 & 43 & 63 & 33 & 42 & 0 \\
\hline $1969-72$ & 65 & 92 & 86 & 50 & 57 & 33 & 50 & \\
\hline $1965-68$ & $\ldots 77$ & 82 & 57 & 50 & 67 & & & \\
\hline $1961-64$ & 63 & 100 & 73 & 33 & 73 & & & \\
\hline $1957-60$ & 62 & 94 & 80 & 20 & 75 & & & \\
\hline $1953-56$ & 62 & 85 & 80 & & 83 & & & \\
\hline $1949-52$ & 50 & 71 & 56 & & 69 & & & \\
\hline $1945-48$ & 62 & 54 & 45 & & 64 & & & \\
\hline $1941-44$ & 60 & 22 & 44 & & 44 & & & \\
\hline $1937-40$ & 64 & 25 & 44 & & & & & \\
\hline $1933-36$ & …................... 33 & 38 & & & & & & \\
\hline $1929-32$ & …................... & 29 & & & & & & \\
\hline $1925-28$ & ......................... & 22 & & & & & & \\
\hline $1921-24$ & ...................... & 29 & & & & & & \\
\hline $1917-20$ & 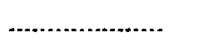 & 50 & & & & & & \\
\hline $1913-16$ & 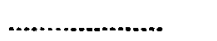 & 40 & & & & & & \\
\hline
\end{tabular}

When the backlog of an agency is defined as the number of cases pending at the end of the year divided by the total number of cases processed, backlogs appear to be unrelated to agency age (Table 12). Only the National Transportation Society Board is faced with a constantly growing backlog. Although the backlog for each agency is a large percentage of disposed cases indicating the agencies' procedures are fairly slow, the backlogs in general do not show the predicted increasing trend.

Table 12. Agengy Bagklogs - Percentage of Cases Pending at End of Year

\begin{tabular}{|c|c|c|c|c|c|c|c|c|}
\hline \multirow[b]{2}{*}{ Year } & & \multicolumn{7}{|c|}{ Agrncy. } \\
\hline & $\overline{F C C}$ & $F T C$ & $N L R B$ & $F A A$ & $C A B$ & $P S A$ & $N T S B$ & $O S H A$ \\
\hline $1973-75$ & 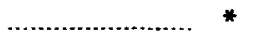 & $*$ & * & * & 33 & * & 50 & * \\
\hline $1969-72$ & 40 & 64 & 24 & * & 28 & * & 34 & * \\
\hline $1965-68$ & . 33 & 48 & 27 & * & 21 & & & \\
\hline $1961-64$ & 34 & 47 & 23 & * & 20 & & & \\
\hline $1957-60$ & …. 29 & 44 & 27 & * & 23 & & & \\
\hline $1953-56$ & 29 & $55 \dagger$ & 23 & & $26 \dagger$ & & & \\
\hline $1949-52$ & .................... 40 & 65 & 21 & & 23 & & & \\
\hline $1945-48$ & 45 & 72 & 28 & & 37 & & & \\
\hline $1941-44$ & 20 & 43 & 23 & & 34 & & & \\
\hline $1937-40$ & 40 & 42 & 38 & & & & & \\
\hline 1929-32 & (....................... & 47 & & & & & & \\
\hline $1933-36$ & . & 41 & & & & & & \\
\hline $1925-28$ & (....................... & 45 & & & & & & \\
\hline $1921-24$ & (....................... & 43 & & & & & & \\
\hline $1917-20$ & …..................... & 40 & & & & & & \\
\hline $1913-16$ & ......................... & 51 & & & & & & \\
\hline
\end{tabular}

* Data not available.

$\dagger$ Agency redefines its workload. 


\section{Western Political Quarterly}

TAble 13. Agency Efficiency Ratios (Workload Divmed by Personnel)

\begin{tabular}{|c|c|c|c|c|c|c|c|c|}
\hline \multirow[b]{2}{*}{ Year } & \multicolumn{8}{|c|}{ Agency } \\
\hline & FCC & FTC & $N L R B$ & $F A A$ & $G A B$ & $P S A$ & $N T S B$ & OSHA \\
\hline $1973-75$ & $*$ & $*$ & 6.1 & $*$ & 39.7 & * & .67 & 88.8 \\
\hline $1969-72 \ldots \ldots \ldots \ldots \ldots$ & 8.2 & .23 & 5.7 & $.06 \dagger$ & 30.4 & * & .62 & 42.6 \\
\hline $1965-68 \ldots \ldots \ldots \ldots \ldots$ & 7.6 & .15 & 4.8 & 1.05 & 17.6 & & & \\
\hline $1961-64 \ldots \ldots \ldots \ldots$ & 6.9 & .31 & 4.9 & .87 & 10.1 & & & \\
\hline $1957-60 \ldots$ & 6.3 & .37 & 5.2 & 1.38 & 3.6 & & & \\
\hline $1953-56$ & 5.1 & $.32 \dagger$ & 4.6 & & 3.6 & & & \\
\hline 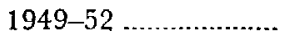 & 3.8 & .63 & 7.3 & & 4.1 & & & \\
\hline $1945-48$ & 3.0 & .61 & 8.6 & & 5.6 & & & \\
\hline $1941-44$ & $3.8 \dagger$ & .87 & 5.0 & & 2.2 & & & \\
\hline $1937-40$ & 11.8 & 1.17 & 3.9 & & & & & \\
\hline 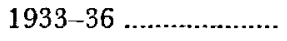 & & 1.50 & & & & & & \\
\hline 1929-32 .......................... & & 1.77 & & & & & & \\
\hline 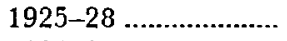 & & 2.00 & & & & & & \\
\hline 1921-24 ......................... & & 1.94 & & & & & & \\
\hline $1917-20$ & & .99 & & & & & & \\
\hline 1913-16 ................... & & .36 & & & & & & \\
\hline
\end{tabular}

* Data not available.

$\dagger$ Agency redefines its workload.

Neither, according to Table 13, does agency efficiency decline with age. Because agency efficiency is defined as the number of cases processed divided by the number of full time personnel, however, the figures in Table 13 should be viewed with some skepticism. First, the demand for agency services is totally outside the control of these agencies; this fact accounts for the increased efficiency of the NLRB after World War II when a large number of war-delayed cases hit the Board. The figures may not reflect, therefore, the agency's capacity but rather the demands on it. Second, agencies from time to time change their definition of their outputs mak-

TABLE 14. Correlations Between Agency Age and Selegted Dependent Variables

\begin{tabular}{|c|c|c|c|c|c|c|c|c|}
\hline \multirow[b]{2}{*}{ Dependent Variable } & \multicolumn{8}{|c|}{ AGENCY } \\
\hline & FCC & $F T C$ & $N L R B$ & $F A A$ & $C A B$ & $P S A$ & $N T S B$ & OSHA \\
\hline \multicolumn{9}{|l|}{ Support } \\
\hline \multicolumn{9}{|c|}{ Congress } \\
\hline Bud. Grth ................ & -.19 & -.17 & -.36 & -.44 & -.17 & -.45 & -.92 & * \\
\hline Personnel Growth ...... & -.24 & -.15 & -.30 & -.57 & -.26 & -.24 & -.61 & .87 \\
\hline Pres. Grth ......................... & -.24 & -.02 & -.33 & -.63 & -.62 & -.92 & -.95 & * \\
\hline Success Rate .............. & -.20 & .33 & -.19 & .46 & .28 & .73 & .69 & * \\
\hline \multicolumn{9}{|l|}{ Interest Relationship } \\
\hline Recruitment ................ & .44 & .41 & -.62 & -.91 & -.63 & * & .07 & * \\
\hline Retirement ................... & .14 & -.03 & -.60 & -.85 & -.61 & * & * & * \\
\hline Group Support .............. & .10 & .01 & .21 & .01 & .17 & -.73 & * & .93 \\
\hline \multicolumn{9}{|l|}{ Rigidity } \\
\hline Turnover & .10 & .09 & -.24 & .07 & -.12 & $*$ & .07 & .87 \\
\hline 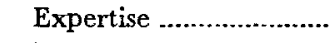 & -.13 & .34 & .68 & .10 & .31 & $*$ & $*$ & * \\
\hline 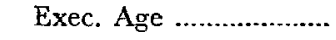 & .23 & -.07 & .71 & .89 & .88 & .80 & -.34 & .87 \\
\hline Lawyers ........................ & .21 & .87 & .63 & .03 & .05 & .08 & -.72 & * \\
\hline Backlogs & -.10 & .11 & -.31 & * & -.41 & * & .85 & * \\
\hline Efficiency ...................... & .09 & -.61 & .06 & -.41 & .81 & * & .80 & .75 \\
\hline
\end{tabular}

* Data insufficient to calculate correlations. 
ing comparisons within agencies difficult. ${ }^{26}$ Despite these limitations only the FTC and the FAA show a decline in agency "efficiency." In both cases the agency redefined their workloads and reported a smaller portion of their activities making this support of the theory's predictions highly questionable.

\section{Conclusions}

Three hypotheses derived from Bernstein's theory of regulatory agency decay were tested. Diffuse political support, as predicted, is negatively related to agency age; but this is because new agencies' support drops off rapidly. After the first few years diffuse support has no relationship with an agency's age. The relationship between the industry and the agency also fails to conform to the prediction. The interchange of personnel between agency and industry actually declines with time. Public statements of interest group support do increase with time, but the relationship is slight.

The key aspect of Bernstein's theory is the relationship between rigidity and age. This study found that as an agency aged, the average age of its executives increased and more of the executives had legal training. Contrary to predictions, however, aging agencies do not have increased turnover, decreased expertise, increased backlogs, or decreased efficiency. Glearly age is not fundamental to the decline of regulatory agencies.

Based on the results presented above, the future does not look bright for an aging theory of regulatory agency decay. The results contradict the predictions as often as they confirm them. Faced with such negative and random results, should Bernstein's theory of regulatory agency decay be firmly rejected? We think not. This initial analysis only tested the relationship between agency age and the other three variables. It did not probe the relationship between political support and rigidity, between the interest relationship and rigidity, or between political support and the interest relationship. These relationships remain untested. We feel that the model should be revised to keep those aspects that appear plausible and eliminate those that do not. By deleting the age variable and retaining political support, the agency-industry relationship, and agency rigidity, an altered, yet to be tested, model is created. Such a model has an advantage over the initial model in that it allows for a reversal of the decay process when the environment makes certain demands on the agency. This appears plausible in light of recent activity by older agencies such as the FTC. In addition, this model places the causes of rigidity directly with the political environment facing the agency and does not rely on the more difficult life cycle analogy, a position supported by much of organization theory. The model shows enough promise to merit some further empirical testing.

\footnotetext{
* Comparisons across agencies are, of course, impossible because the functions agency's perform are significantly different. This paper has consistently compared only data within agencies where the data is comparable.
} 